\title{
PANENTEÍSMO Y MÍSTICA ACTIVA EN «A DON FRANCISCO GINER DE LOS RÍOS», DE ANTONIO MACHADO ${ }^{1}$
}

\author{
Ángel L. PRieto de Paula \\ Universidad de Alicante
}

\section{Resumen}

El poema necrológico que dedica Antonio Machado a Francisco Giner de los Ríos es un retrato moral del homenajeado, pero también una proyección de la personalidad del poeta, que presta su voz para que el muerto exponga a sus discípulos el núcleo de su doctrina. El tema de la composición constituye un modelo ético en el que se confunden dos propuestas morales hasta convertirse en una sola: la del «santo laico» que ha prevalecido como denominador común de algunos reformadores de la España contemporánea, quienes, ante el ocaso de las creencias tradicionales, habilitaron una nueva religión racional y sin dogmas, pero con estrictos principios de comportamiento.

Palabras clave: Francisco Giner de los Ríos; Antonio Machado; mística; panteísmo.

\begin{abstract}
The necrological poem that Antonio Machado dedicates to Francisco Giner de los Ríos is a moral portrait of the honoree, but also a projection of the personality of the poet, who lends his voice for the dead man to expose to his disciples the core of his doctrine. The theme of the composition constitutes an ethical model in which two moral proposals are conflated into a single one: that of the "secular saint», which has

1. Este artículo es una revisión de «Panenteísmo y mística activa en Antonio Machado (sobre "A don Francisco Giner de los Ríos")», capítulo de mi libro La lira de Arión: de poesía y poetas españoles del siglo XX, Alicante, Universidad de Alicante, 1991, pp. 55-84. Elimino de él algunas referencias preliminares a la filosofía krausista, y mantengo el grueso del comentario, con las matizaciones que he creído pertinentes. Dada su condición de reedición, aunque revisada, de un texto ya publicado, con el que he pretendido sumarme al homenaje a Giner, no ha podido seguirse en este caso el método de selección mediante pares ciegos al que se han sometido las restantes colaboraciones del presente volumen.
\end{abstract}


prevailed as a common denominator among some of the reformers of contemporary Spain, who, facing the decline of traditional beliefs, enabled a new rational religion without dogmas, but with strict principles of behaviour.

Keywords: Francisco Giner de los Ríos; Antonio Machado; mysticism; pantheism.

\section{Propuestas tras un derrumbe}

Desde mediados del XIX, el consolador universo de la fe amenazaba derrumbe, sin que la anquilosis de las religiones positivas pudiera responder a la desorientación provocada. Sin embargo, la heterodoxia religiosa, y hasta el ateísmo militante, precisaban para su expresión literaria una vinculación funcional a esas creencias desvitalizadas. Los edificios doctrinales en construcción obedecían aún a las necesidades que cubría la vieja religiosidad. En España, los cascotes del desmoronamiento llegarían hasta la época modernista. En palabras de Ricardo Gullón, a los escritores del momento (Unamuno y Ángel Ganivet, Antonio Machado y Juan Ramón, Azorín y Baroja) «[1] a burocratización de las religiones y la erosión de las creencias les dejó desamparados frente a la muerte» (en Castillo, 1968: 378). Y así como en la Antigüedad la presencia de los dioses y, en general, de lo sobrenatural e inexplicable hundía al hombre en un estado de thambos, estupor provocado por el asedio de seres o instancias superiores (Festugière, 1944: 41-42), en este momento histórico el thambos ya no tiene aquel sentido primigenio: no serán los dioses, sino su ausencia, el motivo de la zozobra. A los embates que sufría un mundo zarandeado, a veces caprichosamente, por fuerzas divinas, sucede ahora un silencio planetario, un territorio espiritual vacío.

En esta situación, la penetración española del krausismo, en la segunda mitad del Ochocientos, supuso el injerto de un espiritualismo racionalista, basado en un sistema de integraciones, en el tronco de una religiosidad en crisis y de una estructura social necesitada de renovación. Sobre el soporte de Fichte, Schelling o Hegel, este sistema de armonización se alejaba del sensualismo como negación de lo ultrasensible, del materialismo como negación del espíritu, del idealismo que supusiera —y solamente de éluna negación de la realidad exterior, del fatalismo como negación de la libertad y, finalmente, del ateísmo como negación de Dios. Y así como el krausismo recaló ferazmente en España, al punto de que casi podría decirse que se hizo en España, sus ecos son perceptibles mucho tiempo después de su repliegue oficial, como lo muestra el poema de Antonio Machado «A don Francisco Giner de los Ríos». 
Sanz del Río, tan importador como, etimológicamente, inventor del krausismo, había propiciado una regeneración moral que no pasaba por la revolución ni los cambios forzados, sino por la colaboración con la historia. En cambio sus discípulos, urgidos favorablemente por los acontecimientos de la Gloriosa en 1868 y una vez desaparecido el maestro en 1869, no se limitaron a allanar las dificultades, sino que quisieron acelerar el curso natural de su meliorismo, ocupando rectorados o ministerios, en marcha hacia el mundo de universal armonía al que aspiraban. Con la Restauración, roto el espejismo de la utopía racional y desalentados, desperdigados o recluidos en el ostracismo los primeros krausistas, los más constantes pasaron, algunos de grado y otros resignadamente, a la acción pedagógica. La ILE (1876) marca ya un periodo de decadencia, donde el racionalismo armónico termina contaminado de positivismo cientificista, dando paso al krausopositivismo, especie de alianza contra natura que trata de acomodar el idealismo krausista al signo de los tiempos. Es la época en que la doctrina es sustituida por el ejemplo, y la metafísica en que consistía se convierte en una ancilla ethicae (Rodríguez de Lecea, 1982: 60). De ese ejemplo moral, difundido mediante la colonización krausista, hizo la caricatura Menéndez Pelayo, subrayando su condición de fruto de una logia francmasónica, fratría o secta:

Se ayudaban y se protegían unos a otros; cuando mandaban, se repartían las cátedras como botín conquistado; todos hablaban igual, todos vestían igual, todos se parecían en su aspecto exterior, aunque no se pareciesen antes, porque el krausismo es cosa que imprime carácter y modifica hasta las fisonomías, asimilándolas al perfil de D. Julián o D. Nicolás. Todos eran tétricos, cejijuntos, sombríos; todos respondían por fórmulas hasta en las insulseces de la vida práctica y diaria; siempre en su papel; siempre sabios, siempre absortos en la vista real de lo absoluto (1956: 1091).

Imposible resulta imaginar la obra teorética de Sanz, y su concepción misional de la enseñanza, sin tener en cuenta el fervor religioso. Para estos utopistas, la recreación de Dios en la vida de los hombres configuraba la historia humana como curso de perfeccionamiento que comienza en la edad simple, en que brilla lo germinal y la pureza mágica del paraíso primigenio, pasa por la edad opositiva y culmina en la edad armónica, con el ingreso del hombre en la «ciudad de Dios en la tierra». El impulso teológico pretendía integrarse sin violencia en el cristianismo, al margen del panteísmo hegeliano: el referido fervor no se detiene en la filantropía o el amor al prójimo, sino que incluye la oración a Jesús y la comunión frecuente. 
El nunca suficientemente aclarado panenteísmo krausista acogía en su seno idealismo germano y cristianismo latino, racionalismo y mística activa, ascetismo e iluminismo. La creencia en un Ser Absoluto no muy distinto del Ser Supremo de la Ilustración dieciochesca, situado sobre la realidad mundanal, les hace equidistar tanto del teísmo (disociación Diosmundo) como del panteísmo (confusión Dios-mundo); o, lo que viene a ser igual, los lleva a participar de uno y de otro, manteniendo cierta concepción dual propia del teísmo, pero sobre una integración del ente divino en la realidad cósmica, sin llegar a la fusión panteísta. En este orden de cosas, las religiones positivas eran entendidas por los krausistas como un paso intermedio en un proceso evolutivo de perfeccionamiento. En el umbral de la plenitud, pretendían salvar lo que las religiones históricas tienen de valor, particularmente el sentimiento de amor universal del cristianismo. Poco a poco fue asentándose la idea de una religión racional, que antes de los ataques furibundos de los impugnadores integristas podía asimilarse al cristianismo sin problemas (mucho más difícilmente al catolicismo incluso entendido de manera liberal). Esta religión había de ser compatible, primero, con la razón; segundo, con la libertad humana. Para un krausista de la primera hornada como Giner, núcleo de estas páginas y del poema de Antonio Machado del que se ocupan, «no hay ni puede haber género alguno de antagonismo entre la Religión del Mesías y la libertad fundada por ella sobre bases indestructibles» (1922: 326). Otra cosa era la ganga litúrgica (rituales, milagrería, jerarquías eclesiales) y el conjunto de adherencias dogmáticas y formales que convirtió el cristianismo, en cuanto doctrina moral de Jesús, en su desviación católica, eclesiástica, formularia y rígida. Aunque tampoco conviene extremar parecidos y minimizar disensiones, como hace Alain Guy refiriéndose a Sanz del Río cuando escribe que «cabe preguntarse si no sería simplemente que iba adelantado a su tiempo y si el Concilio Vaticano II no hubiera aceptado la mayor parte de sus tendencias» $(1985: 253)^{2}$.

Ello así, es lógico pensar que las relaciones entre el hombre y ese Ser Supremo que no precisaba de tramoya milagrosa ni aparato litúrgico,

2. La consideración del krausismo como un catolicismo más o menos desprovisto de su coraza dogmática decimonónica es muy habitual; así, en A. Jiménez-Landi puede leerse: «Los deseos de don Fernando [de Castro] y las palabras de don Julián, que parecían heréticas hace cien años, y, sin duda, se pronunciaban con intenciones poco ortodoxas, hoy, no obstante, resultan una profecía. Lo peor para las mentes reaccionarias, y aun para la misma Iglesia, es que los profetas del Concilio Vaticano segundo hayan sido, en parte, precisamente los heterodoxos» (1973: 158). 
deberían establecerse libremente y de modo directo, como una conexión íntima que se produjera, en la pretensión de Sanz del Río, en la conciencia del hombre. Algo, por cierto, que queda muy cerca de la «Profesión de fe» del vicario saboyano en el Émile (1762) de Rousseau, un referente no solo educacional para los profesores institucionistas: la figura de Jesucristo aparece como canon en la medida en que es portador de una contrastada belleza moral, a la que Sócrates, por ejemplo, solo se acerca3; y el Evangelio, pese a estar poblado de cosas increíbles que repugnan a la razón humana, ensombrece a los libros de los filósofos. Un poco más allá y tenemos la religión de Fernando de Castro, a quien con tanta crueldad trató Menéndez Pelayo, el cual se chancea (luego de muerto y, según el airado santanderino, condenado) del antiguo clérigo reducido al estado seglar cuando proponía una Iglesia universal con un culto sincrético, cuyos sacerdotes serían los ancianos y sus santos los fundadores de religiones y hombres famosos, de Buda a Sócrates, de Zoroastro a Lutero, de San Agustín a Fénelon, de Séneca a Cervantes, de Marco Aurelio a Santa Teresa, de Cristo a Copérnico (1956: 1161).

Aceptando sin reservas la sinceridad religiosa de los krausistas, parece que el catolicismo liberal era solo un paso, más breve de lo que hubiera resultado sin la intransigencia eclesiástica, que no se detenía ahí, sino que conducía al alejamiento del estricto catolicismo. Resulta en cierto modo patético el inicial afán krausista por conciliar razón y fe; un anhelo que, en cuanto tal, presenta algún parecido, por su esforzado voluntarismo, con el intelectualismo tomista. Pero, pujante la doctrina novísima, la Iglesia católica se encargó de enconar las posturas: el inconcluso Concilio Vaticano I (1869-1870) convocado por Pío IX proclamó el dogma de la infalibilidad papal, fijó las relaciones entre razón y fe, definió la revelación y atacó el racionalismo; y el racionalismo y el panteísmo fueron dos de

3. «Cuando Platón pinta a su justo imaginario cubierto por todo el oprobio del crimen y digno de todos los premios de la virtud, pinta rasgo a rasgo a Jesucristo, el parecido es tan sorprendente que todos los Padres lo han percibido y es imposible engañarse en ese punto. ¡Qué prejuicios, qué ceguera no hay que tener para osar comparar el hijo de Sofronisco con el hijo de María! ¡Qué distancia del uno al otro! [...] La muerte de Sócrates filosofando tranquilamente con sus amigos es la más dulce que se pueda desear; la de Jesús expirando en los tormentos, injuriado, burlado, maldecido por todo un pueblo es la más horrible que se pueda temer; al tomar la copa envenenada Sócrates bendice a quien se la presenta y que llora; en medio de un suplicio horroroso, Jesús ruega por sus encarnizados verdugos. Sí, si la vida y la muerte de Sócrates son de un sabio, la vida y la muerte de Jesús son de un Dios» (Rousseau, 1990: 417). 
los errores establecidos también por el primer Syllabus (1864), inspirado asimismo por el citado Papa.

Se ha afirmado en repetidas ocasiones que, sin la hostilidad sufrida por los representantes del krausismo, este apenas hubiera dejado rastro de su paso. No creo que sea cierto, como sí lo es el que, fruto de esa hostilidad, se precipitara el divorcio definitivo con la Iglesia católica y acabara la ilusión conciliadora de catolicismo y libertad individual. Algunos krausistas expresaron angustiadamente sus contradicciones, avances y retrocesos. Así, Gumersindo de Azcárate afirma en su Minuta de un testamento, palpitante autobiografía espiritual: «yo podía continuar rezando el Padre Nuestro, que aprendiera de labios de mi inolvidable madre; pero no podía recitar aquel Credo que también ella me enseñara, pero que definitivamente no era ya el mío» (1876: 32). Entre actitudes como esa y las de otros más extremistas, como Fernando de Castro, que se refiere al Papa como Vicedios en la tierra, las posturas más frecuentes fueron las de quienes abandonaron el dogma católico como resultado de los avances del positivismo; un positivismo que, al cabo, resultaba tan opuesto al catolicismo doctrinal como al romántico idealismo krausista. Sirva de ejemplo el del penalista de la Universidad de Salamanca Dorado Montero, quien, en una carta que remite a Federico Urales, tras elogiar la flexibilidad con que trataba Giner en sus clases de Filosofía del Derecho el tema del catolicismo, viene a concluir serenamente que la propia cultura, las lecturas sin más, le han hecho perder la fe (en Urales, 1977: 93-94)4. Y no deben extrañar los ires y venires de tantos seguidores de Sanz del Río cuando el propio Sanz, ante el hostigamiento de Ortí y Lara y de Aparisi y Guijarro, que lo acusaban de panteísta y corruptor de la juventud estudiosa, llega a proclamar su plena ortodoxia católica («Carta y cuenta de conducta», 1865).

Tal vez el punto más brumoso de la religiosidad krausista sea la actitud ante la inmortalidad individual. Parece que las vagas referencias a una reintegración cósmica de naturaleza panteísta, considerada como mera engañifa por Unamuno, no solventaron la angustia personal de muchos de ellos. De cualquier forma, el aspecto teórico del pensamiento sobre la

4. Federico Urales (pseud. de Juan Montseny) solicitó a diversos intelectuales (Pompeyo Gener, Unamuno, Santiago Rusiñol, Juan Maragall, Eduardo Marquina, Dorado Montero, etc.) que especificaran sus raíces culturales y los escritores que les habían influido más. El objetivo de tales consultas era la redacción de La evolución de la filosofía en España, que publicó en Revista Blanca entre 1900 y 1902. Una parte de ese estudio (la que arranca de los orígenes del socialismo español) se recoge, con idéntico título, en el volumen citado (Urales, 1977). 
religión —si esta es ligazón entre hombre y Dios, hombre y naturaleza, hombre y otros hombres - se encuentra necesariamente orientado a lo moral, lo mismo que la filosofía de la historia o que la lógica, que la epistemología o que la estética. Todas esas y otras disciplinas adquieren pronto entonación prescriptiva y una indisimulable vertiente ética.

\section{El Giner de Antonio Machado}

Sobre esta conexión entre inmortalidad individual y dechado moral versa el poema necrológico que dedicó Antonio Machado a don Francisco Giner de los Ríos. Convengamos en que su interés es doble: permite un acercamiento a Giner a través de la semblanza trazada por uno de sus conocedores más cercanos, y, al lado, nos da acceso al hombre que lo escribió. La afirmación de Unamuno de que el biógrafo termina escribiendo siempre su autobiografía es más que una boutade; un ejemplo lo ofrece este poema, donde se produce la confluencia, me parece, entre ambas figuras: la de Antonio Machado y la de Francisco Giner de los Ríos.

El poema, cuyo pie reza «Baeza, 21 de febrero de 1915», apareció publicado el 26 de febrero en la revista España. No se demoró mucho tiempo Machado en componerlo: Giner había muerto el 18 de febrero. El hecho de que pueda confrontarse, y no solo a efectos de interpretaciones dudosas, con una necrológica en prosa que Machado publicó en el baezano Idea Nueva el 23 de febrero de 1915, ofrece un interés añadido al texto lírico, en el que se entreveran la semblanza humana del muerto y la exposición de ideas religiosas y morales de índole krausista, filtradas ambas en el tamiz del autor.

La relación de Machado con Giner había comenzado muy temprano. $\mathrm{Su}$ abuelo, don Antonio Machado y Núnez (naturalista y difusor del darwinismo en España), y su mismo padre, don Antonio Machado y Álvarez, el folclorista Demófilo, fueron activos proinstitucionistas. Con el traslado a Madrid del abuelo, seguido por toda la familia, Manuel y Antonio Machado pasaron a estudiar en la Institución Libre de Enseñanza, asunto del que hay mucho dicho (AA. VV., 2012-2013) y en el que no vamos a profundizar aquí. Antonio cursó allí sus estudios desde 1883 hasta 1888. Su relación afectiva con la Institución, frente a la confesada aversión al Instituto y a la Universidad, queda explicitada en una nota que escribió a comienzos de 1913:

Me eduqué en la Institución Libre de Enseñanza y conservo gran amor a mis maestros: Giner de los Ríos, el imponderable, Cossío, Caso, Sela, 
Sama (ya muerto), Rubio, Costa (D. Joaquín —a quien no volví a ver desde mis nueve años-). Pasé por el Instituto y la Universidad, pero de estos centros no conservo más huella que una gran aversión a todo lo académico (Machado, III, 1988: 1524).

En parecidos términos se expresa en una carta a Juan Ramón Jiménez escrita por las mismas fechas (ibid.: 1521). Todavía el consejo de Giner llevaría a Machado a abandonar su proyecto de colocarse en el Banco de España y a preparar oposiciones a cátedras de institutos en la disciplina de francés.

Pero vayamos ya al poema (Machado, II, 1989: 587-588), el CXXXIX de la reunión de sus poesías completas:

Como se fue el maestro,

la luz de esta mañana

me dijo: Van tres días

que mi hermano Francisco no trabaja.

5 ¿Murió?... Solo sabemos

que se nos fue por una senda clara,

diciéndonos: Hacedme

un duelo de labores y esperanzas.

Sed buenos y no más, sed lo que he sido

10 entre vosotros: alma.

Vivid, la vida sigue,

los muertos mueren y las sombras pasan;

lleva quien deja y vive el que ha vivido.

¡Yunques, sonad; enmudeced, campanas!

15 Y hacia otra luz más pura

partió el hermano de la luz del alba,

del sol de los talleres,

el viejo alegre de la vida santa.

...Oh, sí, llevad, amigos,

20 su cuerpo a la montaña,

a los azules montes

del ancho Guadarrama.

Allí hay barrancos hondos

de pinos verdes donde el viento canta.

25 Su corazón repose

bajo una encina casta,

en tierra de tomillos, donde juegan

mariposas doradas...

Allí el maestro un día

30 soñaba un nuevo florecer de España. 
La composición fue incluida por Machado en la versión ampliada de Campos de Castilla que aparecería en sus Poesías completas de 1917. Es mucho más, desde luego, que un mero poema de circunstancias, según lo parecen otros de la serie «Elogios» que encabeza, en la que ensalza a escritores como Azorín, Juan Ramón, Valle-Inclán, Rubén, Ortega o Unamuno.

Del talante espiritual de Giner solo vamos a hablar aquí al trasluz de los versos de Antonio Machado. Si queremos asomarnos excepcionalmente fuera, no lo haremos atendiendo a los testimonios de sus discípulos, fervorosos y concluyentes, sino al de Menéndez Pelayo, tan poco dado a la indulgencia con cuantos intelectuales olieran algo a krausismo, y tan especialmente áspero con Sanz del Río, Salmerón y Fernando de Castro. Pues bien, el polígrafo cántabro resulta parcamente contemporizador con Giner, de quien resalta su capacidad propagandista, pues podía «convertir en krausistas hasta las piedras; hombre honradísimo por otra parte, sectario convencido y de buena fe» (Menéndez Pelayo, 1956: 1163).

Los versos reproducidos aluden, claro, a la muerte de Giner; sin embargo, no estamos ante un poema fúnebre o elegiaco, ni aparece en él tratada la muerte con las habituales notas de aflicción y abatimiento. Por el contrario, ella da plenitud a la vida del maestro, al tiempo que plantea una exigencia moral a quienes quedan en la tierra: la del trabajo, la de la pureza, la de la bondad, la de la esperanza en una patria mejor, según la hermosa utopía hispanokrausista de dignificación de la vida española y mejoramiento del mundo.

El poema, silva arromanzada con sencillas asonancias á-a en los versos pares, no presenta «apartados» cerrados, pero tiene diversos tramos distinguibles a lo largo de sus treinta versos. Tras el comienzo (vv. 1-4), con una referencia indirecta a la muerte del maestro, los versos siguientes (5-14) recogen las reflexiones de Machado y la propia propuesta moral de Giner. Desde el verso 15 se exponen los pensamientos de Machado, que alude en el mismo plano al cuerpo del maestro fallecido, al paisaje que amó y donde se propone que sea enterrado, y, en fin, a la regeneración de España soñada por aquel.

Por las circunstancias que motivaron el poema, y aun por tratar este un asunto filosófico como el de la trascendencia individual, es central la referencia a la muerte. Sin embargo, no hay nada de la tanatofanía católica, con su aparatosa espectacularidad («Sic transit...»); por el contrario, «A don Francisco Giner de los Ríos» es un poema vitalista, de incitación a la existencia en plenitud. La lobreguez de la muerte está alumbrada por una luz que refulge, y hasta el propio término muerte está soslayado. La de don 
Francisco no ocurre en el poema: ocurrió antes, y el «murió» se convierte en un «se fue» (v. 1). Por lo mismo, en el verso 4 accedemos a una afirmación que debe leerse más allá de su epidermis: «mi hermano Francisco no trabaja». Lo mismo da decir que el hermano Francisco ha muerto, pero, sobre la elusión del término muerte, se eleva ahora una primera propuesta moral: trabajo igual a vida.

El vitalismo del poema está emparentado con el espíritu del franciscanismo, que lo permea por completo: alegría, austeridad, castidad, limpieza de alma... El tratamiento dado al «hermano Francisco» del comienzo, quien es, a su vez, «hermano de la luz del alba, / del sol de los talleres», nos conduce a un universo de amor y sencillez, de comunicación con la naturaleza, en una suerte de laus criaturarum... Todo ello nos recuerda, es evidente, al otro hermano Francisco, «il poverello d'Assisi», más atento al ejercicio cordial que a las acartonadas rigideces teológicas.

El poema va desgranando un largo muestrario de iluminaciones y chispazos religiosos y morales: luz epifánica y claridad solar (vv. 2, 6, 15, 17) como camino de elevación (v. 20). A la luz y a la altura se accede mediante la misma operación del espíritu humano. Al lado, asimilación de vida a trabajo (vv. 3-4), bondad (v. 9) como componente esencial del espíritu (v. 10), vitalismo que huye del regodeo funeral (vv. 11-14), pureza (v. 26), fraternidad (vv. 4, 16-17, 19), alegría (v. 18), magisterio (vv. 1, 29). Pese a su aire espiritual, nada hay en el poema que recuerde esa cuestión religiosa con cuya presencia «el alma española suena a cartón piedra» (Machado, III, 1988: 1519).

Son tres los pilares que sostienen el peso de los versos: 1) muerte sustraída a las notas con que habitualmente se nos presenta; 2) tendencia a hacer el bien como término de sí mismo, sin interesada búsqueda de un premio ulterior; y 3) espíritu globalizador que fusiona o re-liga —religiosamente - individuo, naturaleza y coro humano. ¿Qué relación guardan estos tres pilares con la doctrina krausista? En Ideal de la humanidad para la vida, una obra donde Julián Sanz del Río reconduce y recrea con su pluma el original de Krause, figuran unos «Mandamientos de la humanidad» que fueron lo más leído - y en muchos casos lo único entendido- de su autor (López-Morillas, 1980: 82-83). De estos mandamientos, especie de grageas que condensan las lecciones del maestro, unos son generales y otros particulares. Fijémonos, por lo que respecta a nuestro propósito, en dos de ellos. Reza así el segundo (de los generales):

Debes conocer, amar y santificar la naturaleza, el espíritu, la humanidad sobre todo individuo natural, espiritual y humano (Krause, 1860: 100). 
Y el decimotercero, primero a su vez de los particulares «y prohibitivos»:

Debes hacer el bien, no por la esperanza, ni por el temor, ni por el goce, sino por su propia bondad: entonces sentirás en ti la esperanza firme en Dios y vivirás sin temor ni egoísmo y con santo respeto hacia los decretos divinos (ibid.).

La primera de las referidas tres ideas-clave conecta estrechamente con la tercera. Una se cierra en la otra circularmente. La muerte no es desintegración en la nada, sino que alimenta a la vida; el hombre revierte en la naturaleza. Los elementos del mundo natural aparecen henchidos de divinidad, y de humanidad también, en una mostración de la pathetic fallacy: la luz habla y llama hermano a Francisco; el viento canta; la encina está vestida con atributos de castidad; las mariposas de oro juegan en tierra de tomillos. El poema brilla con ese encendimiento prosopopéyico de los elementos naturales, que configuran el espacio sagrado donde debe descansar Giner. Los epítetos crean una atmósfera de desnudez y autenticidad, precisamente en tanto que depuran sin añadir nada desde un ángulo puramente representativo: hondos barrancos, verdes pinos. La naturaleza se señala con sustantivos referidos al mundo de las realidades elementales: río, sierra, barranco, encina. Junto a los sustantivos, adjetivos de sencillo cromatismo: azules montes, pinos verdes, mariposas doradas. Antes de que los dos versos finales ( Allí el maestro un día / soñaba un nuevo florecer de España») cierren el poema con su aliento regeneracionista y nos desciendan al corazón de la patria y de los otros hombres, en esos paisajes de pureza que tanto amó el maestro se produce la reintegración, una particular forma de unión en una naturaleza animada: volver a la tierra para cerrar - y proseguir - el ciclo de la vida.

El esbozo de este territorio animado tiene mucho en común con el locus amonus, por lo que hace al espacio, pero también con un illud tempus no retrospectivo a lo lejos, como es lo usual, sino prospectivo y profético. Paraíso y edad de oro. El paraíso conoce numerosas expresiones literarias, pero suele presentarse como encuentro y fusión armónica; así en las profecías bíblicas $^{5}$. El franciscanismo hermana las fuerzas enemigas en la vigorosa literatura de Isaías, mucho antes de la entrada en escena de los fraticelli. Y aunque la edad de oro se sitúa generalmente, como hemos

5. «Habitará el lobo con el cordero, / y el leopardo se acostará con el cabrito, / y comerán juntos el becerro y el león, / y un niño pequeño los pastoreará» (Is 12, 6). En 62, 25 algo similar: «El lobo y el cordero pacerán juntos; / el león, como el buey, comerá paja, / y la serpiente comerá polvo». 
señalado, en el pasado remoto a la manera hesiódica, aquí la bondad, la verdad y la belleza son proyección del presente hacia el futuro mejor. Mediante el mejoramiento progresivo hacia el porvenir utópico: así es la corriente de pensamiento krausista que nutre la composición.

Siguiendo con ambos bastiones de significado (ideas primera y tercera: muerte arrancada a la muerte; y fusión entre individuo, naturaleza y coro humano), cabe preguntarse por el tratamiento que el poema presta a la inmortalidad individual. Aunque no directas, sí hay alusiones a ello, que pueden contrastarse, además, con el artículo necrológico que Machado escribió en los días siguientes a la muerte de Giner, y que en algunos párrafos parece un guion escrupulosamente tenido en cuenta para redactar el poema.

En los versos 5 y 6 tenemos una primera clave: «¿Murió?... Solo sabemos / que se nos fue por una senda clara». Como no se trata aquí de la muy palmaria muerte física, y tampoco nos hallamos ante una pregunta retórica (que sería más inane que inocua), hay que concebir la pregunta en un nivel de trascendencia: «¿Murió?» Esto es: ¿Ha muerto definitivamente? La religiosidad natural pensaba en un dios como sustancia espiritual de la naturaleza, pero no parece que sea solo un vago panteísmo, sin respuesta positiva acerca de esa inmortalidad individual, el que explique sin más el encogimiento de hombros con que Machado responde a la pregunta que él mismo formula: "Solo sabemos...». Y tampoco parece únicamente desdén de Machado hacia las formulillas adormecedoras de la Iglesia católica aplicadas de manera mecánica ${ }^{6}$. Ni únicamente desdén, ni únicamente serenidad ante la reintegración panteísta, el «Solo sabemos...» apunta a la ignorancia real del destino humano y, con ello, a la certidumbre ética de que ese destino no debe condicionar la vida del hombre.

6. En esa especie de currículum que citábamos atrás, y que escribió el poeta a comienzos de 1913, afirma Machado: «Estimo oportuno combatir a la Iglesia católica y proclamar el derecho del pueblo a la conciencia y estoy convencido de que España morirá por asfixia espiritual si no rompe ese lazo de hierro». Líneas más abajo, concluye: «Admiro a Costa, pero mi maestro es Unamuno» (Machado, III, 1988: 1525). Esta referencia admirativa a Unamuno, y las numerosas que le dedicó en otras ocasiones, pueden hacer pensar que lo que ataca Machado, en la línea del vasco, no es tanto el dogma católico cuanto la inercia espiritual engendradora de hipocresía, conformismo y «falta de virilidad espiritual» (ibid.). 


\section{Significado de un emblema}

El poema cede en este punto la voz al muerto (vv. 7-14), en lo que podemos considerar su testamento ideológico (claro que redactado por Machado, el autor-demiurgo). Tras la invitación al trabajo, Giner propone como norma de conducta — segunda idea nuclear a que antes nos hemos referido, y decimotercer mandamiento de Ideal de la humanidad - la persecución del bien en sí mismo: «Sed buenos y no más» (cursiva mía); nada importa el provecho o la falta de provecho que de ello se desprenda. Pero el corazón de la composición está en los versos 11-14, y, dentro de ellos, en el 13:

Vivid, la vida sigue,
los muertos mueren y las sombras pasan;
lleva quien deja y vive el que ha vivido.
¡Yunques, sonad; enmudeced, campanas!

No nos detendremos en la incitación más evidente: la de honrar al muerto mediante la vida laboriosa (símbolo positivo: yunque, glorificación del trabajo como insignia moral), no mediante el lamento esterilizador (símbolo negativo: campana, ostentación luctuosa del dolor); ni siquiera en una algo menos obvia ( «Vivid, la vida sigue, / los muertos mueren...») que remite a una formulación evangélica («deja a los muertos enterrar a sus muertos», Mt 8, 22; Lc 9, 20). Detengámonos, más bien, en el verso 13: «lleva quien deja y vive el que ha vivido». Exactamente, ¿cuál es el significado de este emblema?

Veámoslo así: sobre lo incierto de la otra vida, al hombre contingente solo le es dado actuar en esta; única o no, nuestra capacidad de acción se ciñe al ahora, de modo que la hipotética posesión futura se nutre de lo que cosechamos en el presente. Si hubiera que granjearse por merecimiento algún futuro, este es el único camino ${ }^{7}$; pero si no fuera así, igualmente el hombre debería actuar, y actuar «igualmente» (tal que si sus hechos hubieran de hacerlo acreedor a ese premio inexistente), contraído al único ámbito en el que su acción cobra sentido y se agota. Lo cual nos remite a Senancour y su Obermann, en una reflexión traída a colación a menudo por Unamuno: «si la nada nos está reservada, hagamos que sea una injusticia» (carta XC). Pero ello es así no por una vaga idea estoica que, como en la

7. En esta línea se pronuncia Fernando de Castro en su Memoria testamentaria (1874), publicada póstumamente, en la que da cuenta de su particular credo religioso, y donde afirma, tras pedir que no intervenga clérigo alguno en sus exequias: «estoy persuadido de que lo que más recomienda el alma a Dios, no son los rezos y las misas del sacerdote, sino las buenas obras que se hubieren hecho en vida» (en Jiménez-Landi, 1973: 400). 
novela alpina de Senancour, obliga a una resistencia independiente de lo que haya al cabo, como el soldado que queda en pie dentro de su armadura ya muerto; sino porque en el ideal ético krausista el bien — punto segundo al que nos vamos a referir pronto- se autojustifica, sin proyectarse interesadamente en otra cosa. En suma, si solo se posee como un mérito aquello que se ha ofrecido como una desinteresada donación, entonces «lleva quien deja», tiene el que da. Y, por ende, «vive el que ha vivido»: vive (un presente proyectado al futuro: vivir la vida tras la muerte, si es que existe esa vida; vivir la vida presente, si es la única) quien ha vivido esta sin considerarla mero objeto de transacción.

El poeta ha usado, para marcar las insistencias, de las fórmulas paralelísticas («la vida sigue», «los muertos mueren», «las sombras pasan»; enseguida: «lleva quien deja», «vive el que ha vivido»), para concluir en un quiasmo: «iYunques, sonad; enmudeced, campanas!». Los imperativos, ahora como antes (Hacedme, Sed, Vivid, sonad, enmudeced), son expresión pedagógica de la lección del maestro. El estilo apretado del poema se esponja en la semblanza necrológica publicada en Idea Nueva (Machado, III, 1988: 1575-1577):

... Y hace unos días se nos marchó, no sabemos adónde. Yo pienso que se fue hacia la luz. Jamás creeré en su muerte. Solo pasan para siempre los muertos y las sombras, los que no vivían la propia vida. Yo creo que solo mueren definitivamente - perdonadme esta fe un tanto herética一, sin salvación posible, los malvados y los farsantes, esos hombres de presa que llamamos caciques, esos repugnantes cucañistas que se dicen políticos, los histriones de todos los escenarios, los fariseos de todos los cultos, y que muchos cuyas estatuas de bronce enmohece el tiempo, han muerto aquí y, probablemente, allá, aunque sus nombres se conserven escritos en pedestales marmóreos.

De la índole moral de Giner afirma en el mismo artículo Machado:

Era don Francisco Giner un hombre incapaz de mentir e incapaz de callar la verdad; pero su espíritu fino, delicado, no podía adoptar la forma tosca y violenta de la franqueza catalana, derivaba necesariamente hacia la ironía, una ironía desconcertante y cáustica, con la cual no pretendía nunca herir o denigrar a su prójimo, sino mejorarle. Como todos los grandes andaluces, era don Francisco la viva antítesis del andaluz de pandereta, del andaluz mueble, jactancioso, hiperbolizante y amigo de lo que brilla y de lo que truena. Carecía de vanidades, pero no de orgullo; convencido de ser, desdeñaba el aparentar. Era sencillo, austero hasta la santidad, amigo de las proporciones justas y de las medidas cabales. Era un místico, 
pero no contemplativo y extático, sino laborioso y activo. Tenía el alma fundadora de Teresa de Ávila y de Íñigo de Loyola; pero él se adueñaba de los espíritus por la libertad y por el amor.

Era —lo dice Machado- un místico «laborioso y activo», cuyo ejercicio espiritual provoca elevación, sublimación de la materia, donación a los hombres. En otras palabras: el amor como término de sí mismo (segunda idea sustantiva del poema).

En efecto, tras la invitación al trabajo («Hacedme / un duelo de labores y esperanzas»), Giner ha señalado como norma de conducta la persecución desinteresada del bien («Sed buenos y no más»), incluso poniéndose a sí mismo como dechado ( «sed lo que he sido / entre vosotros: alma»). Dicho en primera persona, esto puede interpretarse como jactancia, o al menos como expresión del «orgullo modesto, que es lo español y lo cristiano» que aconsejaba el apócrifo Juan de Mairena a sus alumnos, si no fuera porque constituye una deriva de la voz del poeta hacia el psiquismo de quien está hablando; en otras palabras, un elogio que formula Machado sobre Giner y que canaliza en la voz del propio Giner, así autoelogiado. (Juzgue cada quien si lo que se gana en inmediatez conativa con la primera persona compensa lo que se pierde en imagen de la humildad que se pretende conseguir; yo pienso que no).

En realidad, este ejercicio espiritual es más devocional que propiamente místico. En su oscilante vinculación entre la bondad utilitaria y la bondad desinteresada, la literatura espiritual española ha bandeado entre ortodoxia y heterodoxia. El bien por el bien como precepto de Dios: esta máxima de Krause («perogrullada» la llama Menéndez Pelayo, que la adscribe sin más a la ética kantiana) es de raigambre estrictamente cristiana, sin que quepan en esto reservas como las que expresa el referido autor cuando afirma que tal fórmula sería en efecto cristiana, «y de las más corrientes si no supiéramos lo que significa la palabra Dios en todo sistema panteístico» (Menéndez Pelayo, 1956: 1081). Un fuerte curso religioso había recogido las brasas sanjuanistas hasta llegar a predicar la indiferencia absoluta con respecto a cualquier bien, no ya solo futuro y alcanzable, sino presente: la sumisión a la divinidad exigía total independencia espiritual con respecto a la pulsión de salvación. Esto adquiere sublimación espiritual en el soneto «A Cristo crucificado» del Siglo de Oro, cuyo anónimo autor, que asume la ortodoxia católica a los efectos teóricos, desvincula de aquella su comportamiento moral, dominado por una simpatía pietista que expresa su amor al Cristo doliente al margen de premios o castigos: «No me mueve, mi Dios, para quererte / el cielo que me tienes prometido; 
/ ni me mueve el infierno tan temido / para dejar por eso de ofenderte»...; con el corolario de la determinación de amar a Jesús no ya sobre todas las cosas, sino al margen de todas las cosas: «pues aunque cuanto espero no esperara, / lo mismo que te quiero te quisiera» (en Blecua, 1987: 175176). Recordemos también, por contraste, las Coplas manriqueñas, en las que se encarece el buen comportamiento como pago para la obtención del premio de la vida futura.

Pero el desprendimiento de los intereses, manifestado tanto en «A Cristo crucificado» como en la semblanza machadiana de don Francisco Giner, tiene una larguísima tradición en la literatura de los espirituales de varias épocas: el Maestro Eckhart, y Taulero, y San Juan de la Cruz, y Miguel de la Fuente, y Miguel de Molinos... Angelus Silesius (Johann Scheffler), autor de El querubín peregrino, encerró en su célebre aforismo sobre la rosa esa manera de obrar que se agota en sí misma: «La rosa es sin porqué, florece porque florece». El molinosismo predicó la doctrina quietista que llevó el despego y la negación del propio interés hasta los extremos que siguen (radicalizada versión del «me hice perdidiza, y fui ganada», del Cántico sanjuanista):

Sabrás que se ha de desapegar y negar de cinco cosas el que ha de llegar a la ciencia mística. La primera, de las criaturas; la segunda, de las cosas temporales; la tercera, de los mismos dones del Espíritu Santo; la cuarta, de sí misma, y la quinta, se ha de desapegar del mismo Dios. Esta última es la más perfecta, porque el alma que así se sabe solamente desapegar es la que se llega a perder en Dios, y solo la que así se llega a perder es la que se acierta a hallar (III, 176) .

Con el molinosismo concuerdan los krausistas en el despego y la humildad, pero no en el nihilismo quietista (pues ellos son hombres de acción, si no revolucionaria sí reformadora); y tampoco concuerdan en el odio de sí, que le hace a Molinos afirmar: «No tiene humildad interior el que no se aborrece a sí mismo con un mortal odio, pero pacífico y quieto. No llegará jamás a alcanzar este tesoro el que no tuviere un bajo y profundísimo conocimiento de su vileza, de su hediondez y miseria» (III, 103). Un amor tan negador, en fin, que le llevaría a la misma negación del amor y al más radical abismarse en la nada: «no mires nada, no desees nada, no quieras nada...» (III, 195).

8. Cito especificando «libro» y entrada numérica; sigo la edición de José Ángel Valente (1990). 
La renovación espiritual a que tendían estos idealistas muestra estrechas afinidades con rasgos erasmistas, como son el afán de interiorización y el desdén por las manifestaciones litúrgicas externas ${ }^{9}$, notas patentes en el poema (enmudecimiento de las campanas), y de manera mucho más explícita en la citada necrológica en prosa. Afirma en ella Machado: «Desdeñaba don Francisco Giner todo lo aparatoso, lo decorativo, lo solemne, lo ritual, el inerte y pintado caparazón que acompaña a las cosas del espíritu y que acaba siempre por ahogarlas» (Machado, III, 1988: 1576). Esencia erasmista que recoge —o de la que participa- el krausismo.

El poema camina hacia la integración, como confluencia y desembocadura de las llamadas dispersas a lo largo de la composición. El verso 15 marca una inflexión en el tono, al inicio de ese proceso integratorio: el viejo Giner marcha «hacia otra luz más pura». Aparece ahí entrevista la dualidad, mediante un sistema de correspondencias: luz atenuada por la opacidad del existir, por un lado; luz «más pura», sin obstáculos ni cendales, por otro. Una vez muerto y la tarea cumplida, «el viejo alegre de la vida santa» habita ya la naturaleza divinizada. A partir del verso 19, y tras la solicitación autorial a los amigos de que entierren el cuerpo del maestro en su amada Sierra de Guadarrama, el poema se demora en la descripción anticlimática, y de talante panteísta, de una naturaleza animada, esto es, vertebrada por el soplo creador que hace - ya se ha dicho- que el viento cante, las encinas se invistan de castidad, jugueteen las mariposas (trasunto de la mariposa tricolor que, tras la muerte de Platero, el burrillo

9. Krause y Erasmo no solo coinciden, respecto a su integración cultural en España, en el hecho de que a uno y a otro se les prestara más atención en España que en sus países de nacimiento. También lo hacen en que su pensamiento logró avivar el aletargado talante filosófico español, que en el caso del krausismo terminó propiciando un modo de filosofía «nacional» (Posada, 1981: 25 ss.). Con razonamientos diversos, numerosos autores (Azorín, Fernando de los Ríos, Joaquín Xirau, Eloy Terrón, Elías Díaz, José Luis Abellán, etc.) creen que el krausismo, como antaño el erasmismo, es «español» en la medida en que no solo se ajustaba a las necesidades nacionales de reforma, sino también porque España, al contacto con la doctrina foránea, dio forma a un pensamiento que permanecía en estado latente, lo que quiere al cabo decir que encontró en el krausismo aquello que estaba buscando. La idea de que el pensamiento español «se hizo krausista» por casualidad —o por pereza intelectual de Sanz del Río- procede de Menéndez Pelayo, quien propaló la especie de que Julián Sanz del Río tropezó azarosamente con el krausismo en su viaje de estudios a Alemania, como lo podría haber hecho con cualquier otra corriente de pensamiento. En su incidencia en la religiosidad española, erasmismo y krausismo no coinciden tanto en el corazón doctrinal como en la necesidad, en el XVI igual que en el XIX, de vitalizar una espiritualidad ahogada en ostentaciones litúrgicas, y reprobar la corrupción e hipocresía de las costumbres. 
cuya historia había encandilado al agonizante don Francisco, se irisaba cuando se cruzaba con el rayo solar que se colaba por el ventanuco de la cuadra). Y no deja de ser reseñable, por lo sugerente a unos y por lo enojoso a otros, que la imagen machadiana del nuevo alborear de la patria con que se cierra el poema, al hilo de la particular religión del Guadarrama de la que el maestro Giner era el sumo sacerdote («Allí el maestro un día / soñaba un nuevo florecer de España»), sirviera años después a los poetas fascistas para poetizar la estampa de un país amaneciente donde comenzaba a reír la primavera.

El poema ajusta tensamente la naturaleza de lo cantado a unas palabras que rehúyen las metáforas ostentosas y los bruñidos juegos verbales. Los suaves engarces sintácticos y las frecuentes esticomitias van trenzando un discretísimo encadenamiento - mera enumeración normalmente- de ritmo e ideas. La serenidad de la composición es compatible, sin embargo, con la abundancia de apóstrofes e imperativos, vocativos, exclamaciones: «Sed buenos», «Vivid», «Yunques, sonad; enmudeced, campanas», «Oh sí, llevad, amigos»... Son, todos ellos, elementos acordes con la entonación parenética y exhortatoria de carácter «magisterial», como corresponde a la elevación del canon ético que se propone.

Machado dibuja la etopeya de un texto vivo, cuya ejemplaridad ética arrastra más que los libros en que se expone su doctrina. En estos versos se quintaesencian las estancias plurales de la novísima filosofía krausista (y, por irradiación, gineriana y aun machadiana): amor al trabajo, moralidad radical, tolerancia, espiritualidad en que se hermanan naturaleza y hombre, sencillez franciscana, patriotismo. Gumersindo de Azcárate lo resumía así en Minuta de un testamento, donde daba cuenta de su alejamiento de la Iglesia: "como ideal práctico la vida santa de Jesús, como regla de conducta una moral pura y desinteresada, como ley social el amor y la caridad, como dogma el Sermón de la Montaña, como culto la Oración dominical» (1876: 31-32). Y Sanz del Río, maestro del maestro de Machado, había instado a sus discípulos: «Dejad tras de vuestro nombre un rastro de bellos ejemplos y doctrinas, y una memoria sin tacha».

Tan hermoso ideario encontró, además, un poeta que lo convirtió arte. «A don Francisco Giner de los Ríos» es, por todo lo anterior, un monumento grávido de pensamiento y estremecido de emoción: un poema mayor, sin duda, en la obra de don Antonio Machado «el bueno». 


\section{Bibliografía citada}

AA. VV., La Institución Libre de Enseñanza y Francisco Giner de los Ríos: nuevas perspectivas, 3 vols., Madrid, Fundación Francisco Giner de los Ríos / Institución Libre de Enseñanza / ACE / Residencia de Estudiantes, 2012-2013.

[AzCÁrate, G. de], Minuta de un testamento, publicada y anotada por W..., Madrid, Impr. J. M. Pérez, 1876.

Blecua, J. M. (ed.), Poesía de la Edad de Oro. II: Barroco, Madrid, Castalia, 1987.

Castillo, H. (ed.), Estudios críticos sobre el Modernismo, Madrid, Gredos, 1968.

FESTUGIÈRE, A. J., L'histoire générale des religions. Grece-Rome, Paris, Quillet, 1944.

GINER DE LOS Ríos, F., Estudios filosóficos y religiosos [Obras completas, VI], Madrid, La Lectura, 1922.

GuY, A., Historia de la filosofía española, Barcelona, Anthropos, 1985.

JimÉnEZ-Landi, A., La Institución Libre de Enseñanza, Madrid, Taurus, 1973.

KRAUSE, C. Cr. [sic], Ideal de la humanidad para la vida, con introducción y comentarios por D. Julián Sanz del Río, Madrid, Impr. Manuel Galiano, 1860.

LÓPEZ-Morillas, J., El krausismo español, Madrid, FCE, 1980.

Machado, A., Poesía y prosa, 4 vols., ed. O. Macrì, Madrid, Espasa-Calpe / Fundación Antonio Machado, 1988-1989.

MenÉndez Pelayo, M., Historia de los heterodoxos españoles, II, Madrid, BAC, 1956.

Molinos, M. de, Guía espiritual, ed. J. Á. Valente, Madrid, Alianza, 1990.

PosadA, A., Breve historia del krausismo español, Oviedo, Universidad de Oviedo, 1981.

RodríGuez DE LECEA, T., «La filosofía de la religión del krausismo español», en AA. VV., Reivindicación de Krause, Madrid, Instituto Fe y Secularidad / Fundación Fritz Ebert, 1982.

Rousseau, J. J., Emilio, o de la educación, ed. y trad. M. Armiño, Madrid, Alianza, 1990.

Urales, F. [pseud. de Juan Montseny], La evolución de la filosofía en España, Barcelona, Laia, 1977. 